Log in through your library

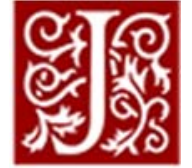

JSTOR

JOURNAL ARTICLE

\title{
Digitalization in the Agribusiness Value Chain and Payment Systems: Evidence from Sub-Saharan Africa
}

Folasade Adegboye

Journal of African Development

Vol. 21, No. 1, SPECIAL ISSUE: Digital Technology and Inclusive Development (Spring 2020), pp. 96-115 (20 pages)

Published By: Penn State University Press

https://doi.org/10.5325/jafrideve.21.1.0096

https://www.jstor.org/stable/10.5325/jafrideve.21.1.0096

Cite this Item

Read and download

Log in through your school or library

Purchase article

$\$ 19.00$ - Download now and later

\section{Preview}

\begin{abstract}
ABSTRACT The African agribusiness sector and those of other developing regions of the world are characterized by disorderly patterns in the value chain system. The agriculture market in Africa has enormous potential with an anticipated size of $\$ 1$ trillion by 2030 . However, the average African farm performs at only $40 \%$ of its potential. Also, consistent increase in population size and a consistent growth rate of above $2.5 \%$ in the region create dire concern for food availability. This study examines the extent to which digitalization affects agribusiness value chain and the payment system in the sub-Saharan African region. The descriptive and pooled ordinary least square regression analysis was employed to determine the statistical significance of digitalization on the payment system and agricultural productivity in the region over the period 2000 to 2019. The results revealed that digitalization has a significant impact on agricultural productivity for the region. The study recommends a wholesome utilization of
\end{abstract}


blockchain technology to ensure better farmland usage, improved access for all stakeholders in the value chain framework, enhanced productivity, food security, and reduced extreme hunger and poverty. This will ensure that Africa will become empowered to feed itself and use its competitive advantage of good weather, arable land, labor, and water to compete globally.

\section{Journal Information}

The Journal of African Development (JAD) was first published in 1988 as Journal of African Finance and Economic Development. It is a top ranked journal in Africa's development economics. It publishes original research papers relating to all aspects of Africa's development economics - from immediate policy concerns to structural economic and development challenges. While the emphasis is on quantitative work that is novel and relevant; groundbreaking theoretical work is highly encouraged. Articles that take up questions on Africa's development economics that are of interest to the general readers of JAD, from both micro and macro perspectives are welcomed. Those that provide in-depth studies of a specific country, region, cross-country, industry, firm, organization(s) or cases, and whose findings are likely to be of great interest to the general readers of JAD, with attainable and specific policy recommendations, will be considered. JAD is the official publication of the African Finance and Economic Association (AFEA). AFEA is a professional Association for academicians and practitioners (government and industry) of economics, finance, and related disciplines with scholarly, professional or other similar interests in the development of Africa. Membership in AFEA is open to individuals and organizations having an interest in the development, understanding, teaching, and application of the principles and theories of economics and finance as they relate to Africa. 